\title{
Application of the Extended Grunwald-Winstein Equation to Solvolyses of $\boldsymbol{n}$-Propyl Chloroformate
}

\author{
Jin Burm Kyong ${ }^{1, *}$, Hoshik Won ${ }^{1}$ and Dennis N. Kevill ${ }^{2, *}$ \\ ${ }^{1}$ Department of Chemistry, Hanyang University, Ansan, Kyunggi-Do 425-791, Korea. \\ ${ }^{2}$ Department of Chemistry and Biochemistry, Northern Illinois University, DeKalb, Illinois 60115-2862, \\ U.S.A. \\ * Authors to whom correspondence should be addressed; e-mail: jbkyong@hanyang.ac.kr; \\ dkevill@niu.edu
}

Dedicated to Professor Marvin Charton on the occasion of his $70^{\text {th }}$ birthday and in recognition of his many contributions to correlation analysis in chemistry and related areas.

Received: 30 November 2004 / Accepted: 10 December 2004 / Published: 31 January 2005

\begin{abstract}
Application of the extended Grunwald-Winstein equation to solvolyses of $n$-propyl chloroformate in a variety of pure and binary solvents indicates an addition-elimination pathway in the majority of the solvents but an ionization pathway in the solvents of highest ionizing power and lowest nucleophilicity. For methanolysis, a solvent deuterium isotope effect of 2.17 is compatible with the incorporation of general-base catalysis into the substitution process. Activation parameters are consistent with the duality of mechanism. Very modest positive salt effects are observed on adding chloride or bromide salts to the ethanolysis.
\end{abstract}

Keywords: n-Propyl chloroformate, addition-elimination, ionization, solvent isotope effect, Grunwald-Winstein equation

\section{Introduction}

The extended Grunwald-Winstein equation (eqn 1) [1-4] is very useful for the correlation of solvolysis reactions: 


$$
\log \left(k / k_{0}\right)_{\mathrm{RX}}=l N_{\mathrm{T}}+m Y_{\mathrm{X}}+c
$$

In equation (1), $k$ and $k_{0}$ represent the specific rates of solvolysis of a substrate (RX) in a given solvent and in the standard solvent (80\% ethanol), respectively; the parameter $l$ represents the sensitivity towards changes in the solvent nucleophilicity $\left(N_{\mathrm{T}}\right)$ [3]; the parameter $m$ represents the sensitivity towards changes in the solvent ionizing power ( $Y_{\mathrm{X}}$ for a leaving group $\mathrm{X}$ ) [4]; and $c$ represents a constant (residual) quantity.

Although both the $N_{\mathrm{T}}$ and $Y_{\mathrm{X}}$ scales are based on standard systems involving substitution reaction at an $\mathrm{sp}^{3}$-hybridized carbon [3, 4], the scales have also been used with considerable success in the correlation analyses of solvolysis reactions of substrates which have attack at the $\mathrm{sp}^{2}$-hybridized carbon of acyl halides [5-7] and chloroformate esters [8-15], at the phosphorus atom of phosphorochloridate esters [16, 17] or amides [18], and at the sulfur atom of arenesulfonyl chlorides [19].

In the studies of the solvolyses of chloroformate esters, the aryl esters [8] solvolyze by a unit mechanism, believed to be addition-elimination (association-dissociation) over the full range of solvent type studied. There is probably general-based catalysis $[20,21]$ to the nucleophilic attack, leading to a relatively high $l$ value of 1.7 for phenyl chloroformate solvolyses. The addition-step is believed to be rate-determining, largely on the basis of the very similar rates for fluoroformates and chloroformates, despite the much stronger carbon-fluorine bond [22].

Solvolyses of $p$-nitrobenzyl chloroformate [13] also follows the addition-elimination pathway over the full range of solvents, but removal of the electron-withdrawing $p$-nitro group causes a changeover to an ionization mechanism, with loss of carbon dioxide leading to both solvolysis and decomposition, in 1,1,1,3,3,3 - hexafluoro-2-propanol (HFIP)-water and 2,2,2-trifluoroethanol (TFE)-water mixtures [13]. For example, in $100 \%$ TFE, the products were 48\% benzyl chloride and 52\% benzyl 2,2,2-trifluoroethyl ether.

The ionization pathway with solvolysis-decomposition is the only one operating for solvolyses of 1-adamantyl chloroformate, with loss of $\mathrm{CO}_{2}$ leading to the relatively stable1-adamantyl cation, which can be captured by simultaneously formed chloride ion or solvent [23]. The lack of any dependence on $N_{\mathrm{T}}$ is consistent with the positive charge at the transition state residing predominantly at the bridgehead carbon of the developing 1-adamantyl cation. The 2-adamantyl chloroformate [15], with the 2-adamantyl group liberated as the cation in solvolyses of the adamantyl p-toluenesulfonates about $10^{5}$ times slower than with the 1-adamantyl group [4, 24], and also the simplest possible secondary-alkyl chloroformate, isopropyl chloroformate [14], show under solvolytic conditions characteristics similar to those of benzyl chloroformate, except that the solvent range for ionization is wider and only in the more nucleophilic and least ionizing solvents (100 and 90\% ethanol and methanol) is the addition-elimination pathway dominant.

The simplest primary alkyl group, ethyl, within the chloroformate leads to solvolyses which continue to show the two competing reaction channels. In this case, however, the addition-elimination pathway dominates over a wide range of solvents and only in formic acid and aqueous mixtures with appreciable fluoroalcohol content is an ionization mechanism dominant. The extended Grunwald-Winstein equation treatment of the ionization region leads to a fairly large $l$ value of 0.69 , which is considered to reflect an efficient solvation of a relatively unhindered developing acylium ion [10]. Solvolyses of methyl chloroformate would be expected to have an even greater tendency towards 
addition-elimination and, indeed, the ionization mechanism appears to be dominant only for $\mathrm{HFIP}-\mathrm{H}_{2} \mathrm{O}$ mixtures with at least 90\% HFIP content [11].

In the present study, we look at the solvolyses of $n$-propyl chloroformate in the usual variety of pure and binary solvents. This allows both a comparison with the solvolyses of the isomeric isopropyl chloroformate and a study of the effect of introducing an S-methyl group into the ethyl chloroformate substrate. In addition to a detailed extended Grunwald-Winstein treatment of the specific rates, the influence of temperature on the specific rates (for five solvents) allows enthalpies and entropies of activation to be calculated, a measurement in methanol- $d$ allows a determination of the solvent deuterium isotope effect, and the effect of added salts containing halide ion upon the specific rate of ethanolysis is studied.

\section{Results}

The specific rates of solvolysis of $n$-propyl chloroformate have been determined, at $25.0{ }^{\circ} \mathrm{C}$, in methanol, ethanol, and TFE and in binary aqueous solvents with the other component being methanol, ethanol, acetone, TFE, or HFIP. Determinations were also made in TFE-ethanol mixtures. In Table 1 are presented the 28 data points used in extended Grunwald-Winstein equation analyses, together with the appropriate $N_{\mathrm{T}}[3]$ and $Y_{\mathrm{Cl}}[4,25]$ values. A determination was also made in methanol-d (MeOD). For five solvents, values were also determined at 35.0, 45.0, and $55.0^{\circ} \mathrm{C}$ and these values, together with activation parameters calculated using all four temperatures, are reported in Table 2 . In ethanol at 25.0 ${ }^{\circ} \mathrm{C}$, a study was made of the influence on the specific rate of addition of up to $0.08 M$ tetraethylammonium chloride or bromide; these specific rates are reported in Table 3.

Table 1. First-order rate coefficients for the solvolysis of $n$-propyl chloroformate in pure and binary solvents at $25.0{ }^{\circ} \mathrm{C}$ together with the appropriate solvent nucleophilicity $\left(N_{\mathrm{T}}\right)$ and solvent ionizing power $\left(Y_{\mathrm{Cl}}\right)$ values.

\begin{tabular}{|c|c|c|c|}
\hline Solvent (\%) ${ }^{a}$ & $10^{5} k\left(\mathrm{~s}^{-1}\right)$ & $N_{\mathrm{T}}^{b}$ & $Y_{\mathrm{Cl}}^{c}$ \\
\hline $100 \% \mathrm{MeOH}^{\mathrm{d}}$ & $8.88 \pm 0.05$ & 0.17 & -1.17 \\
\hline 90\% MeOH & $18.8 \pm 0.2$ & -0.01 & -0.18 \\
\hline 80\% MeOH & $27.7 \pm 0.3$ & -0.06 & 0.67 \\
\hline $70 \% \mathrm{MeOH}$ & $35.7 \pm 0.5$ & -0.40 & 1.46 \\
\hline $60 \% \mathrm{MeOH}$ & $43.7 \pm 0.4$ & -0.54 & 2.07 \\
\hline $100 \% \mathrm{EtOH}$ & $2.20 \pm 0.03$ & 0.37 & -2.52 \\
\hline $90 \% \mathrm{EtOH}$ & $5.64 \pm 0.04$ & 0.16 & -0.94 \\
\hline 80\% EtOH & $7.92 \pm 0.05$ & 0.00 & 0.00 \\
\hline $70 \% \mathrm{EtOH}$ & $9.79 \pm 0.07$ & -0.20 & 0.78 \\
\hline $60 \% \mathrm{EtOH}$ & $12.4 \pm 0.1$ & -0.38 & 1.38 \\
\hline $50 \% \mathrm{EtOH}$ & $16.1 \pm 0.1$ & -0.58 & 2.02 \\
\hline $90 \% \mathrm{Me}_{2} \mathrm{CO}$ & $0.307 \pm 0.003$ & -0.35 & -2.39 \\
\hline $80 \% \mathrm{Me}_{2} \mathrm{CO}$ & $0.942 \pm 0.007$ & -0.37 & -0.80 \\
\hline $70 \% \mathrm{Me}_{2} \mathrm{CO}$ & $1.91 \pm 0.01$ & -0.42 & 0.17 \\
\hline
\end{tabular}


Table 1. Cont.

\begin{tabular}{|c|c|c|c|}
\hline Solvent (\%) ${ }^{a}$ & $10^{5} k\left(\mathrm{~s}^{-1}\right)$ & $N_{\mathrm{T}}^{b}$ & $Y_{\mathrm{Cl}}^{c}$ \\
\hline $60 \% \mathrm{Me}_{2} \mathrm{CO}$ & $3.45 \pm 0.02$ & -0.52 & 1.00 \\
\hline 100\% TFE & $0.0621 \pm 0.006$ & -3.93 & 2.81 \\
\hline 97\% TFE & $0.0650 \pm 0.004$ & -3.30 & 2.83 \\
\hline $90 \% \mathrm{TFE}$ & $0.0935 \pm 0.0002$ & -2.55 & 2.85 \\
\hline $70 \% \mathrm{TFE}$ & $0.591 \pm 0.005$ & -1.98 & 2.96 \\
\hline $50 \% \mathrm{TFE}$ & $1.92 \pm 0.02$ & -1.73 & 3.16 \\
\hline $80 \mathrm{~T}-20 \mathrm{E}^{e}$ & $0.0666 \pm 0.0003$ & -1.76 & 1.89 \\
\hline $60 \mathrm{~T}-40 \mathrm{E}^{e}$ & $0.342 \pm 0.002$ & -0.94 & 0.63 \\
\hline $40 \mathrm{~T}-60 \mathrm{E}^{e}$ & $0.854 \pm 0.008$ & -0.34 & -0.48 \\
\hline $20 \mathrm{~T}-80 \mathrm{E}^{e}$ & $1.60 \pm 0.02$ & 0.08 & -1.42 \\
\hline 97\% HFIP & $0.563 \pm 0.009$ & -5.26 & 5.17 \\
\hline 90\% HFIP & $0.242 \pm 0.004$ & -3.84 & 4.31 \\
\hline 70\% HFIP & $0.499 \pm 0.014$ & -2.94 & 3.83 \\
\hline 50\% HFIP & $1.15 \pm 0.02$ & -2.49 & 3.80 \\
\hline
\end{tabular}

${ }^{a}$ Volume/volume basis at $25.0{ }^{\circ} \mathrm{C}$, except for TFE- $\mathrm{H}_{2} \mathrm{O}$, HFIP- $\mathrm{H}_{2} \mathrm{O}$ mixtures, which are on a weight/weight basis. ${ }^{b}$ Based on the specific rate of solvolysis of the $S$-methyldibenzothiophenium ion (ref. 3). ${ }^{c}$ Based on the specific rates of solvolysis of 1-adamantyl chloride (refs. 4, 25). ${ }^{d}$ First-order rate coefficient of $4.09( \pm 0.03) \times 10^{-5} \mathrm{~s}^{-1}$ in MeOD. ${ }^{e} \mathrm{~T}-\mathrm{E}$ are TFE-ethanol mixtures.

Table 2. Specific rates and activation parameters for the solvolysis of $n$-propyl chloro-formate in pure and aqueous solvents at various temperatures.

\begin{tabular}{|c|c|c|c|c|}
\hline Solvent (\%) & $\begin{array}{c}\text { Temperature } \\
\left({ }^{\circ} \mathrm{C}\right) \\
\end{array}$ & $10^{5} k\left(\sec ^{-1}\right)^{a}$ & $\begin{array}{l}\Delta H+298.15 \\
\left(\mathrm{kcal} \mathrm{mol}^{-1}\right)^{b}\end{array}$ & $\begin{array}{c}\Delta S \neq 298.15 \\
\left(\mathrm{cal} \mathrm{mo} l^{-1} K^{-1}\right)^{b}\end{array}$ \\
\hline \multirow[t]{3}{*}{$100 \mathrm{MeOH}^{\mathrm{C}}$} & 35.0 & $21.2 \pm 0.6$ & & \\
\hline & 45.0 & $41.9 \pm 1.1$ & $13.8 \pm 0.4$ & $-30.5 \pm 1.4$ \\
\hline & 55.0 & $84.4 \pm 2.4$ & & \\
\hline \multirow[t]{3}{*}{$100 \mathrm{EtOH}^{c}$} & 35.0 & $5.19 \pm 0.03$ & & \\
\hline & 45.0 & $11.3 \pm 0.2$ & $14.9 \pm 0.1$ & $-29.6 \pm 0.4$ \\
\hline & 55.0 & $24.4 \pm 0.4$ & & \\
\hline \multirow[t]{3}{*}{$80 \mathrm{EtOH}^{c}$} & 35.0 & $17.3 \pm 0.2$ & & \\
\hline & 45.0 & $37.0 \pm 0.5$ & $13.3 \pm 0.3$ & $-32.2 \pm 1.3$ \\
\hline & 55.0 & $67.5 \pm 2.5$ & & \\
\hline \multirow[t]{3}{*}{$70 \mathrm{TFE}^{d}$} & 35.0 & $1.61 \pm 0.04$ & & \\
\hline & 45.0 & $4.58 \pm 0.04$ & $19.3 \pm 0.5$ & $-17.5 \pm 1.9$ \\
\hline & 55.0 & $12.8 \pm 0.3$ & & \\
\hline \multirow[t]{3}{*}{$70 \mathrm{HFIP}^{d}$} & 35.0 & $1.59 \pm 0.02$ & & \\
\hline & 45.0 & $4.71 \pm 0.07$ & $20.5 \pm 0.1$ & $-13.7 \pm 0.2$ \\
\hline & 55.0 & $13.1 \pm 0.1$ & & \\
\hline
\end{tabular}

${ }^{a}$ Values at $25.0^{\circ} \mathrm{C}$, from Table 1, also used in the calculation of the activation parameters. ${ }^{b}$ With associated standard error. ${ }^{c}$ Volume-volume basis at $25.0^{\circ} \mathrm{C}$. ${ }^{d}$ Weight-weight basis. 
Table 3. Effect of added tetraethylammonium salts upon the specific rates of solvolysis of $n$-propyl chloroformate in ethanol at $25.0^{\circ} \mathrm{C}$.

\begin{tabular}{|c|c|c|}
\hline Salt & Concentration $(M)$ & $105 k(\sec -1)$ \\
\hline \multirow[t]{4}{*}{$\mathrm{NEt}_{4} \mathrm{Cl}$} & 0.0104 & $2.24 \pm 0.01$ \\
\hline & 0.0201 & $2.29 \pm 0.02$ \\
\hline & 0.0410 & $2.41 \pm 0.03$ \\
\hline & 0.0803 & $2.47 \pm 0.02$ \\
\hline \multirow[t]{4}{*}{$\mathrm{NEt}_{4} \mathrm{Br}$} & 0.0101 & $2.25 \pm 0.01$ \\
\hline & 0.0202 & $2.29 \pm 0.02$ \\
\hline & 0.0400 & $2.33 \pm 0.01$ \\
\hline & 0.0801 & $2.46 \pm 0.02$ \\
\hline
\end{tabular}

\section{Discussion}

The specific rates of solvolysis of n-propyl chloroformate are similar to those for ethyl chloroformate (at $24.2{ }^{\circ} \mathrm{C}$ ). For the values within Table 1, values for ethyl chloroformate solvolysis [10] are available for all entries except for $70 \%$ methanol, $50 \%$ ethanol, and $70 \%$ acetone. For 20 of the 25 values available, the value for the $k n-\mathrm{Pr} / k^{\text {Et }}$ ratio is close to unity (range of 0.84 to 1.15 , with an average value of $1.02 \pm 0.09$ ). The other five solvents are all aqueous-fluoroalcohol mixtures, rich in fluoroalcohol, with values for the ratio of 3.5 in 100\% TFE, 2.8 in 97\% TFE, 3.6 in 97\% HFIP, 2.4 in 90\% HFIP, and 1.6 in $90 \%$ TFE. The first four of these solvents were all assigned to the ionization pathway for solvolyses of ethyl chloroformate. The $90 \%$ TFE was assigned to the addition-elimination pathway but the value somewhat higher than unity suggests that there may be a moderate contribution from the ionization pathway to the measured specific rate of solvolysis.

In the extended Grunwald-Winstein analyses of ethyl chloroformate solvolysis, the 70\% HFIP and $50 \%$ HFIP data were assigned to the ionization pathway [10]. The comparison with the presently reported $n$-PrOCOCl data leads to $k^{n-P r} / k^{E t}$ ratios of 1.12 and 0.84 , indicating that the ionization pathway does not automatically lead to elevated values for the $k^{n-\mathrm{Pr}} / k^{\mathrm{Et}}$ ratio. The alternative, that the 70\% HFIP and 50\% HFIP were wrongly assigned was rendered unlikely by the observation that the quality of the correlations for both the ionization and addition-elimination pathways was significantly reduced when these two data points were transferred. Since the 90\% TFE $\left(N_{\mathrm{T}}=-2.55\right)$ has an intermediate value for the ratio and both 70\% HFIP and 50\% HFIP have $N_{\mathrm{T}}$ values less negative than -3 , it is suggested that, for $N_{\mathrm{T}}$ values above -3 , positive charge is appreciably dispersed by nucleophilic solvation and the electron demand within the developing acylium ion is insufficient for the small difference in stabilizing ability between ethyl and $n$-propyl to be detectable. In solvents with lower nucleophilicities, the internal electron demand is sufficient for a weak (factor of about 3 ) distinction, favoring $n$-propyl, to be operative.

A parallel argument involving reductions in electron demand as the solvent nucleophilicity increases was put forward to explain why the Hammett-type Taft $\kappa^{*}$ values [26] for solvolyses of secondary alkyl tosylates fall in magnitude from -9.1 in HFIP, to -5.2 in TFE, to -4.3 in $\mathrm{H}_{2} \mathrm{O}$, to -3.5 in formic acid, and to -2.1 in acetic acid [27]. Similarly, the $\kappa$ value from a conventional Hammett plot increases from -5 in formic acid or $97 \%$ TFE to -1.7 in ethanol for the solvolyses of $p$-substituted benzyl p-toluenesulfonates 
[28]. Smaller effects, but in the identical direction, are observed for solvolyses of 1-aryl-1-tert-butylmethyl chlorides [29].

A treatment of the data of Table 1 in terms of the extended Grunwald-Winstein equation suggests the same division of solvents as for ethyl chloroformate [10]. The majority of the solvents feature solvolysis by the addition-elimination (A-E) mechanism (Scheme 1), and reaction in highly ionizing and weakly nucleophilic fluoroalcohol solvents (100\% TFE, 97\% TFE, 97, 90, 70, 50\% HFIP) favors solvolysis by the ionization pathway (Scheme 2).

\section{Scheme 1.}

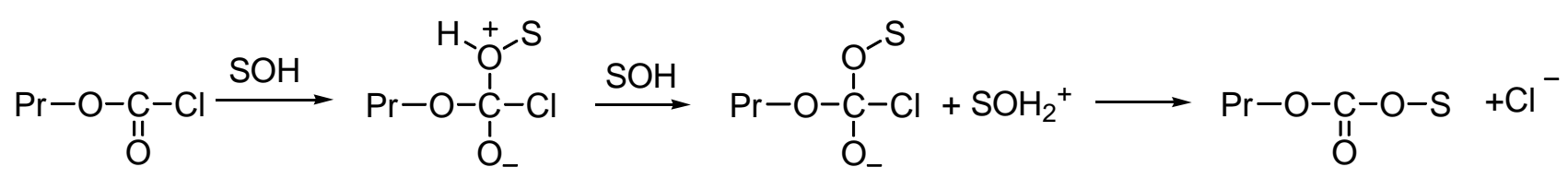
followed, when S = H, by:

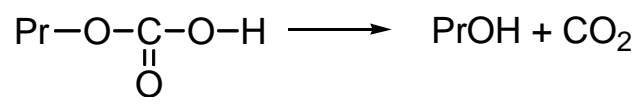

Scheme 2.

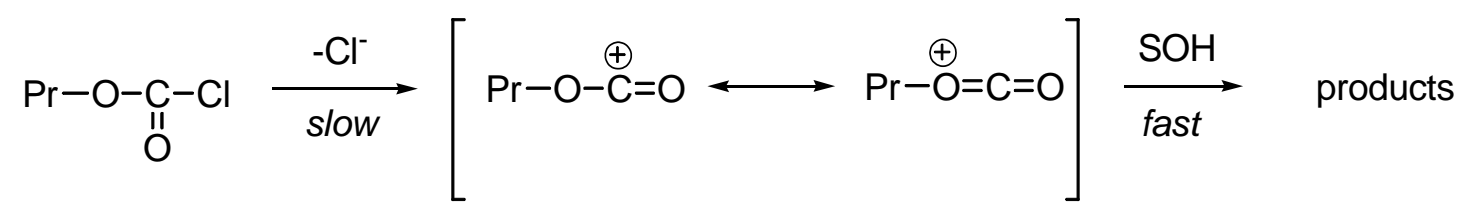

For 22 solvents (from Table 1, except for those mentioned immediately above) the values obtained are essentially identical to those for phenyl chloroformate [8] and for methyl [11] and ethyl chloroformates [10] over similar ranges of solvent composition (Table 4 and Figure 1).

Table 4. Correlation of the specific rates of the solvolyses of methyl, ethyl, $n$-propyl, i-propyl, phenyl, benzyl, 2-adamantyl, and 1-adamantyl chloroformates, and ethyl chlorothioformate, using the extended Grunwald-Winstein equation.

\begin{tabular}{lllcccccc}
\hline Substrate & Mechanism $^{\boldsymbol{a}}$ & $\boldsymbol{n}^{\boldsymbol{b}}$ & $\boldsymbol{l}^{\boldsymbol{c}}$ & $\boldsymbol{m}^{\boldsymbol{c}}$ & $\boldsymbol{c}^{\boldsymbol{c}}$ & $\boldsymbol{l} \boldsymbol{m}$ & $\boldsymbol{R}^{\boldsymbol{d}}$ & $\boldsymbol{F}^{\boldsymbol{e}}$ \\
PhOCOCl & A-E & $21^{f}$ & $1.68 \pm 0.10$ & $0.57 \pm 0.06$ & $0.12 \pm 0.41$ & 2.95 & 0.973 & 159 \\
$\mathrm{MeOCOCl}$ & $\mathrm{A}-\mathrm{E}$ & $19^{g}$ & $1.59 \pm 0.09$ & $0.58 \pm 0.05$ & $0.16 \pm 0.07$ & 2.74 & 0.977 & 171 \\
EtOCOCl & $\mathrm{A}-\mathrm{E}$ & $28^{h}$ & $1.56 \pm 0.09$ & $0.55 \pm 0.03$ & $0.19 \pm 0.24$ & 2.84 & 0.967 & 179 \\
EtOCOCl & $\mathrm{I}$ & $7^{h}$ & $0.69 \pm 0.13$ & $0.82 \pm 0.16$ & $-2.40 \pm 0.27^{i}$ & 0.84 & 0.946 & 17 \\
EtSCOCl & $\mathrm{I}$ & $19^{h}$ & $0.66 \pm 0.08$ & $0.93 \pm 0.07$ & $-0.16 \pm 0.31$ & 0.71 & 0.961 & 96 \\
$n$-PrOCOCl & $\mathrm{A}-\mathrm{E}$ & $22^{j}$ & $1.57 \pm 0.12$ & $0.56 \pm 0.06$ & $0.15 \pm 0.08$ & 2.79 & 0.947 & 83 \\
$n$-PrOCOCl & $\mathrm{I}$ & $6^{j}$ & $0.40 \pm 0.12$ & $0.64 \pm 0.13$ & $-2.45 \pm 0.47^{i}$ & 0.63 & 0.942 & 11 \\
$i$-PrOCOCl & $\mathrm{I}$ & $20^{k}$ & $0.28 \pm 0.05$ & $0.52 \pm 0.03$ & $-0.12 \pm 0.05$ & 0.54 & 0.979 & 192 \\
BzOCOCl & $\mathrm{I}$ & $11^{l}$ & $0.25 \pm 0.05$ & $0.66 \pm 0.06$ & $-2.05 \pm 0.11^{i}$ & 0.38 & 0.976 & 80
\end{tabular}


Table 4. Cont.

\begin{tabular}{clllccccc}
\hline Substrate & Mechanism $^{\boldsymbol{a}}$ & $\boldsymbol{n}^{\boldsymbol{b}}$ & $\boldsymbol{l}^{\boldsymbol{c}}$ & $\boldsymbol{m}^{\boldsymbol{c}}$ & $\boldsymbol{c}^{\boldsymbol{c}}$ & $\boldsymbol{l} \boldsymbol{m}$ & $\boldsymbol{R}^{\boldsymbol{d}}$ & $\boldsymbol{F}^{\boldsymbol{e}}$ \\
\hline 2-AdOCOCl & I & $19^{m}$ & $\sim 0$ & $0.47 \pm 0.03$ & $0.11 \pm 0.19$ & $\sim 0$ & 0.970 & 128 \\
1-AdOCOCl & I & $15^{n}$ & $\sim 0$ & $0.47 \pm 0.03$ & $0.03 \pm 0.05$ & $\sim 0$ & 0.985 & 97 \\
\hline
\end{tabular}

${ }^{a}$ Addition-elimination (A-E) and ionization (I). ${ }^{b}$ Number of solvent systems included in the correlation. ${ }^{c}$ From application of eqn. 1, with associated standard errors. ${ }^{d}$ Correlation coefficient. ${ }^{e}$ F-test value. ${ }^{f}$ From ref. 8. ${ }^{g}>$ From ref. $11 .{ }^{h}>$ From ref. $10 .{ }^{i}$ Large negative value because the experimental $k_{0}$ value is for a system reacting by the A-E pathway. ${ }^{j}$ This study. ${ }^{k}$ From ref. $14 .{ }^{l}$ From ref. $13 .{ }^{m}>$ From ref. $15 .{ }^{n}$ The one-term Grunwald-Winstein equation was used (ref. 23).

With only 6 solvent compositions within the ionization range, the number available is less than the ten considered to be a minimum for a two-term correlation [30]. Accordingly, the values of 0.40 for $l$ and 0.64 for $m$ (Table 4 and Figure 2) must be considered approximate. Nonetheless, the values are in reasonable agreement with others believed to be for ionization reaction in solvolyses of chloroformate esters; several are within the table. The $\mathrm{l} / \mathrm{m}$ ratio has been suggested as a useful mechanistic criterion and the values of Table 4 divide nicely into two classes with values of 2.7 to 3.0 for those entries postulated to represent addition-elimination and 0.38 to 0.84 for those believed to represent ionization. For $n$-propyl chloroformate solvolysis, values for the ratio of 2.79 and 0.63 , respectively, are towards the middle of these ranges.

Figure 1. The plot of $\log \left(k / k_{0}\right)$ vs. $\left(1.57 N_{\mathrm{T}}+0.56 Y_{\mathrm{Cl}}\right)$ for the solvolysis of $n$-propyl chloroformate in pure and binary solvents at $25.0{ }^{\circ} \mathrm{C}$. The data points for $100 \%$ TFE, 97\% TFE, and all HFIP- $\mathrm{H}_{2} \mathrm{O}$ mixtures were not included in the correlation; they are added to the plot to show their considerable deviation from the correlation line. Correlation coefficient (r) is 0.947.

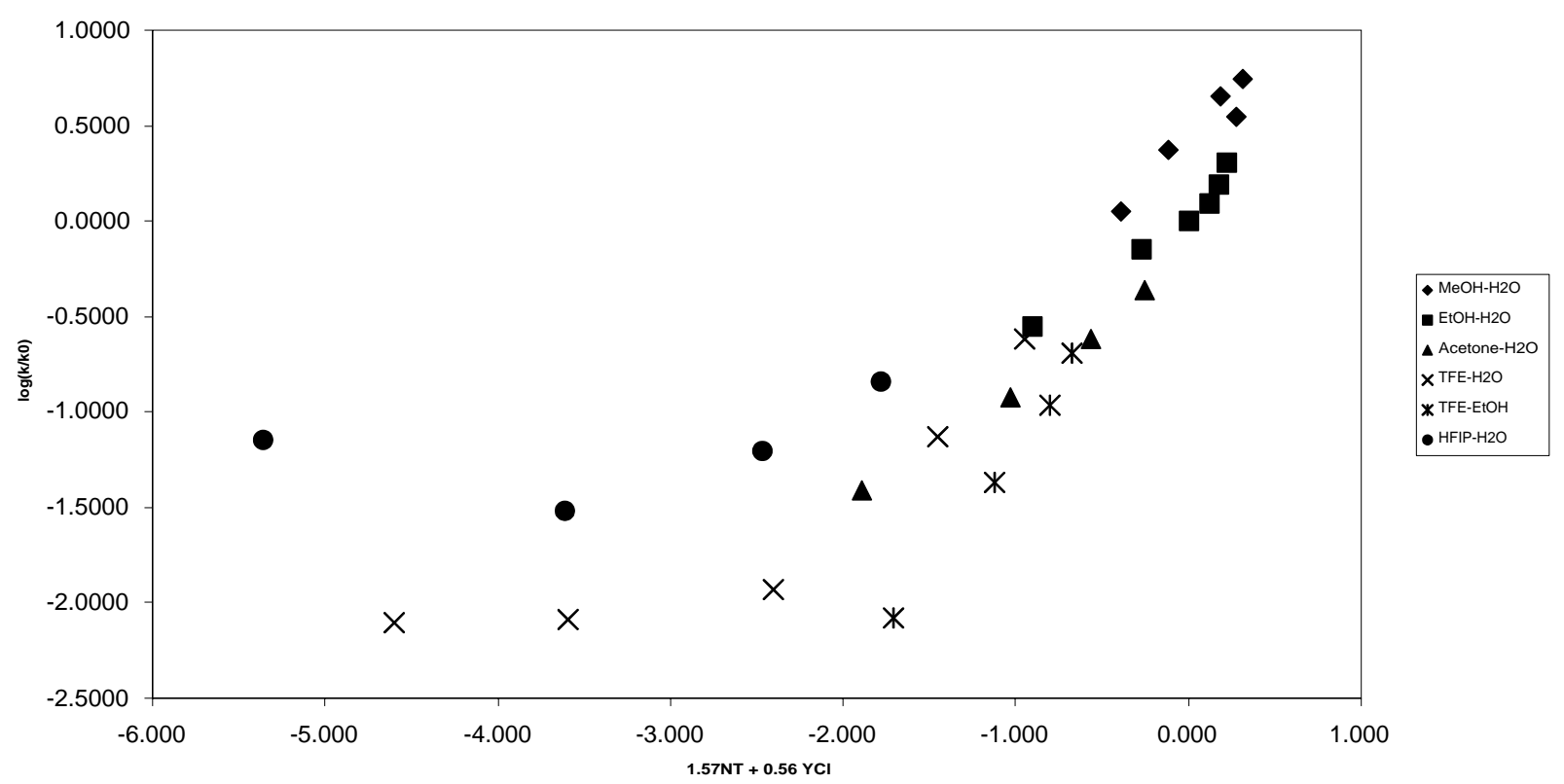

Solvent deuterium isotope effects have previously been studied for several solvolyses of chloroformate esters. In $100 \%$ water, the $k_{\mathrm{H} 2 \mathrm{O}} / k_{\mathrm{D} 2 \mathrm{O}}$ ratio was in the range of 1.8 to 2.0 at $7-25{ }^{\circ} \mathrm{C}$ for a series of substrates believed to react by the bimolecular mechanism. The value for isopropyl 
chloroformate, in the ionization range, was somewhat lower at 1.35 and the value for diphenylcarbamoyl chloride was lower again at 1.1 [31]. More recently, values have become available for corresponding ratios in methanolysis. Values have been reported for the $k_{\mathrm{MeOH}} / k_{\mathrm{MeOD}}$ ratio of 2.1-2.5 for a series of substituted phenyl chloroformates [32, 33], of 2.4 for $p$-nitrobenzyl chloroformate [13], and of 1.9 for 2-adamantyl chloroformate [15]. In the latter value, however, there is probably a contribution from the ionization pathway. The ionization contribution is $12 \%$ in ethanol, and this would be expected to increase somewhat in methanol. The isotope effect value in the present study for methanolysis of $n$-propyl chloroformate (specific rate values from Table 1) is $2.17 \pm 0.03$. Values in the region of 2.1 to 2.5 are generally considered to arise from a bimolecular solvolysis which is accompanied by general-base catalysis [34, 35].

Figure 2. The plot of $\log \left(k / k_{0}\right)$ vs. $\left(0.40 N_{\mathrm{T}}+0.64 Y_{\mathrm{Cl}}\right)$ for the solvolysis of $n$-propyl chloroformate in TFE, 97\% TFE, and aqueous HFIP solvents at $25.0{ }^{\circ} \mathrm{C}$. Correlation coefficient (r) is 0.942 .

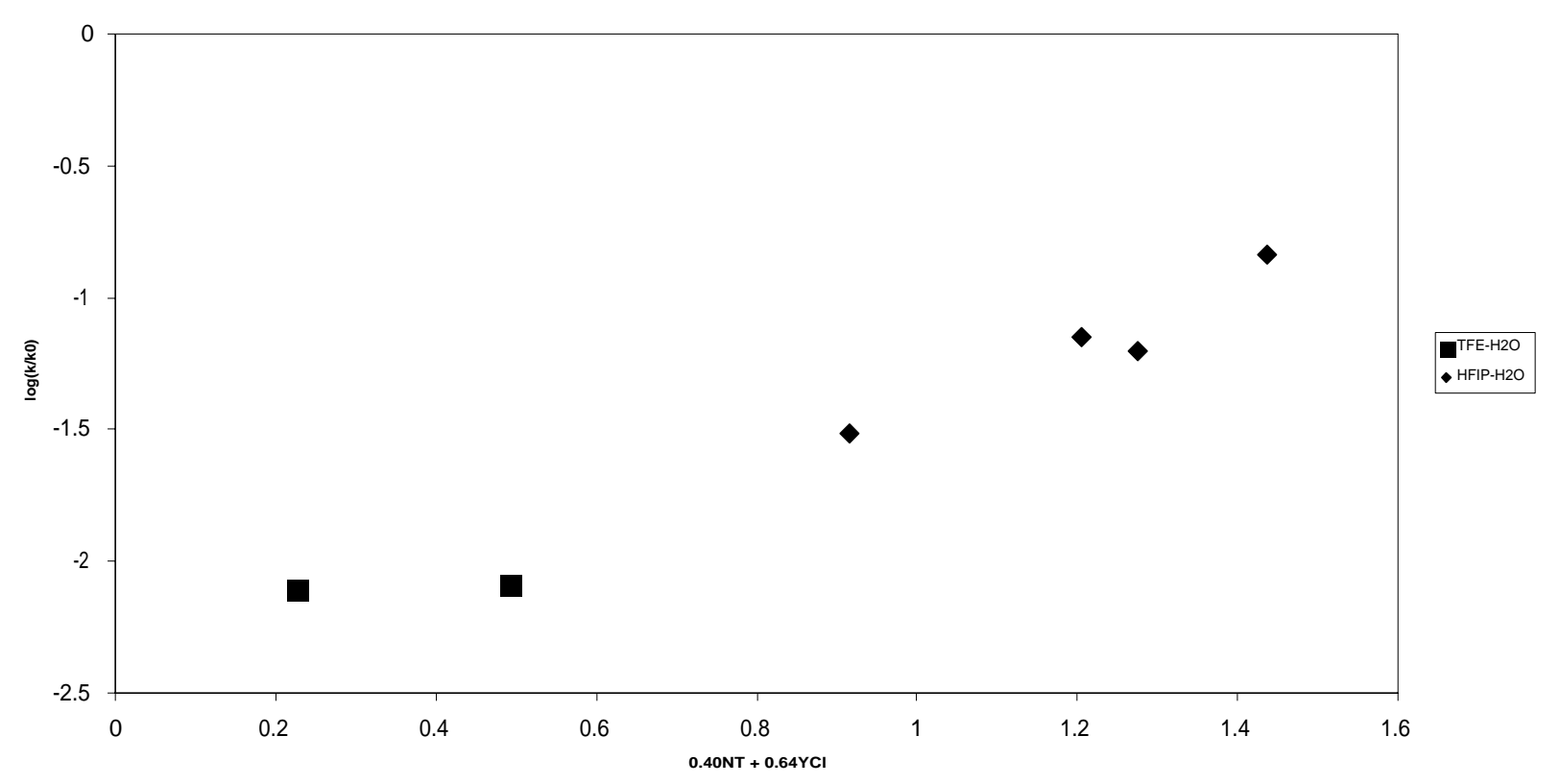

The activation parameters calculated from studies at four temperatures in the $25-55^{\circ} \mathrm{C}$ range are very similar for solvolyses in methanol, ethanol, and 80\% ethanol, with activation energies of from 13.3 to $14.9 \mathrm{kcal} / \mathrm{mole}$ and negative entropies of activation in the range of -29.6 to $-32.2 \mathrm{cal} \mathrm{mol}^{-1} \mathrm{~K}^{-1}$, as would be expected for a process involving general-base catalysis to a bimolecular attack. At the other mechanistic extreme in 70\% HFIP, the activation energy is increased to $20.5 \mathrm{kcal} / \mathrm{mole}$ and the entropy of activation is considerably less negative at $-13.7 \mathrm{cal} \mathrm{mol}^{-1} \mathrm{~K}^{-1}$. The $70 \%$ HFIP is one of the six solvents where the solvolyses are believed to proceed by an ionization pathway on the basis of the extended Grunwald-Winstein equation. The changes in activation parameters are consistent [36] with the two proposed pathways.

For the ethanolysis, the effect of added tetraethylammonium salts has been studied. Salts containing either chloride and bromide show only modest increases in specific rate when added at concentration of up to $0.08 \mathrm{M}$. The actual increases are virtually identical (Table 3), with both showing a $12 \%$ increase in specific rate at $0.08 \mathrm{M}$ concentration. One might have anticipated, with the bromide salt, a perturbation due to chloride/bromide exchange but this does not seem to occur to any appreciable extent and the 
slight increases are very well explained in terms of a modest salt effect upon the solvolysis. Additions of chloride, bromide, or iodide, as the tetrabutylammonium salts, to the ethanolysis of 1-adamantyl chloroformate had essentially identical small effects (13\% increase at $0.1 \mathrm{M}$ salt), again independent of the identity of the anion [23]. As with the $n$-propyl chloroformate solvolysis, this was taken to indicate that there was no superimposed initial halide exchange.

\section{Conclusions}

The specific rates of solvolysis of $n$-propyl chloroformate show, as the solvent is varied, a large region with a dominant addition-elimination pathway, with addition rate-determining. An extended Grunwald-Winstein equation (eqn. 1) treatment for this region leads to values of $1.57 \pm 0.12$ for $l$ and $0.56 \pm 0.06$ for $m$. The remaining six solvents, fluoroalcohol-rich solvents with high ionizing power and low nucleophilicity, give corresponding values of $0.40 \pm 0.12$ and $0.64 \pm 0.13$, respectively, and a rate-determining ionization is proposed.

The solvent deuterium isotope effect value for methanolysis $\left(k_{\mathrm{MeOH}} / k_{\mathrm{MeOD}}\right)$ of $2.17 \pm 0.03$ is of a magnitude usually taken to indicate that nucleophilic attack by a methanol molecule is assisted by general-base catalysis by a second methanol molecule. The activation parameters for five representative solvolyses are consistent with the division into the two groups. For the addition-elimination process, relative to the ionization process, lower activation energies are accompanied by more negative entropies of activation. Modest positive salt effects are observed on adding either chloride-ion or bromide-ion containing tetraethylammonium salts to the ethanolysis.

\section{Acknowledgements}

Acknowledgement is made to the donors of the American Chemical Society Petroleum Research Fund for partial support of this research.

\section{Experimental}

Solvents were purified and the kinetic runs carried out as previously described [23]. The $n$-propyl chloroformate (Aldrich, 98\%) was used as received. The average values reported for the specific rates were calculated using all points from duplicate runs. The multiple regression analyses were performed using commercial statistical analysis packages.

\section{References}

1. Winstein, S.; Grunwald, E.; Jones, H. W. J. Am. Chem. Soc. 1951, 73, 2700.

2. Schadt, F. L.; Bentley, T. W.; Schleyer, P. v. R. J. Am. Chem. Soc. 1976, 98, 7667.

3. Kevill, D. N. In Advances in Quantitative Structure-Property Relationships, Vol. 1; Charton, M., Ed.; JAI Press: Greenwich, CT, 1996; pp 81-115.

4. Bentley, T. W.; Llewellyn, G. Prog. Phys. Org. Chem. 1990, 17, 121.

5. Kevill, D. N.; D’Souza, M. J. J. Phys. Org. Chem. 2002, 15, 881.

6. D’Souza, M. J.; Stant-Boggs, M. E.; White, R.; Kevill, D. N. J. Chem. Res., Synop. 2003, 775. 
7. Kevill, D. N.; D’Souza, M. J. J. Org. Chem. 2004, 69, 0000.

8. Kevill, D. N.; D’Souza, M. J. J. Chem. Soc., Perkin Trans. 2 1997, 1721.

9. Kevill, D. N.; Bond, M. W.; D’Souza, M. J. J. Org. Chem. 1997, 62, 7869.

10. Kevill, D. N.; D’Souza, M. J. J. Org. Chem. 1998, 63, 2120.

11. Kevill, D. N.; Kim, J. C.; Kyong, J. B. J. Chem. Res., Synop. 1999, 150.

12. Kevill, D. N.; D’Souza, M. J. Can. J. Chem. 1999, 77, 1118.

13. Kyong, J. B.; Park, B.-C.; Kim, C.-B.; Kevill, D. N. J. Org. Chem. 2000, 65, 8051.

14. Kyong, J. B.; Kim, Y.-G.; Kim, D. K.; Kevill, D. N. Bull Korean Chem. Soc. 2000, 21, 662.

15. Kyong, J. B.; Yoo, J. S.; Kevill, D. N. J. Org. Chem. 2003, 68, 3425.

16. Bentley, T. W.; Ebdon, B.; Llewellyn, G.; Abduljaber, M. H.; Miller, B.; Kevill, D. N. J. Chem. Soc., Dalton Trans. 1997, 3819.

17. Kevill, D. N.; Carver, J. S. Org. Biomol. Chem. 2004, 2, 2040.

18. Kevill, D. N.; Miller, B. J. Org. Chem. 2002, 67, 7399.

19. Kevill, D. N.; D’Souza, M. J. Collect. Czech. Chem. Commun. 1999, 64, 1790.

20. Kevill, D. N.; Foss, F. D. J. Am. Chem. Soc. 1969, 91, 5054.

21. Bentley, T. W.; Harris, H. C. J. Org. Chem. 1988, 53, 724.

22. Queen, A.; Nour, T. A. J. Chem. Soc., Perkin Trans. 2 1976, 935.

23. Kevill, D. N.; Kyong, J. B.; Weitl, F. L. J. Org. Chem. 1990, 55, 4304

24. (a) Fort, R. C., Jr.; Schleyer, P. v. R. Chem. Rev. 1964, 64, 277 (b) Kevill, D. N.; Kolwyck, K. C.; Shold, D. M.; Kim, C.-B. J. Am. Chem. Soc. 1973, 95, 6022.

25. (a) Bentley, T. W.; Carter, G. E. J. Am. Chem. Soc., 1982, 104, 5741; (b) Kevill, D. N.; D’Souza, M. J. J. Chem. Res. Synop. 1993, 174; (c) Koo, I. S.; Bentley, T. W.; Kang, D. H.; Lee, I. J. Chem. Soc., Perkin Trans. 2 1991, 296.

26. Shorter, J. Correlation Analysis of Organic Reactivity; Research Studies Press: Letchworth, Herts, U.K. 1982; Chap. 4.

27. Bentley, T. W.; Bowen, C. T.; Morten, D. H.; Schleyer, P. v. R. J. Am. Chem. Soc. 1981, 103, 5466.

28. Kevill, D. N.; Ren, H. J. Org. Chem. 1989, 54, 5654.

29. Liu, K.-T.; Duann, Y.-F.; Yu, D.-G. J. Chin. Chem. Soc. (Taipei) 1998, 45, 153.

30. Abraham, M. H.; Grellier, P. L.; Abboud, J.-L. M.; Doherty, R. M.; Taft, R. W. Can. J. Chem. 1988, 66, 2673.

31. Kivinen, A. In The Chemistry of Acyl Halides; Patai, S., Ed.; Interscience: New York, 1972; pp. 198-200

32. Yew, K. H.; Koh, H. J.; Lee, H. W.; Lee, I. J. Chem. Soc., Perkin Trans. 2 1995, 2263.

33. Koo, I. S.; Yang, K.; Kang, K.; Lee, I. Bull Korean Chem. Soc. 1998, 19, 968.

34. Ryu, Z. H.; Shin, S. H.; Lee, J. P.; Lim, G. T.; Bentley, T. W. J. Chem. Soc., Perkin Trans 2 2002, 1283.

35. Oh, Y. H.; Jang, G. G.; Lim, G. T., Ryu, Z. H. Bull. Kor. Chem. Soc. 2002, 23, 1089.

36. Bunton, C. A. Nucleophilic Substitution at a Saturated Carbon Atom; Elsevier: Amsterdam, 1963; pp. 70-72.

(C) 2005 by MDPI (http://www.mdpi.org). 